\title{
Full - Perspective Analysis of Medium Income Trap
}

\author{
Guangtong Wang ${ }^{1} \&$ Qiang Jiang ${ }^{2}$ \\ ${ }^{1}$ Ph.D of Applied Economics in Center for Global Studies, Shanghai University, Shanghai, China \\ ${ }^{2} \mathrm{Ph} . \mathrm{D}$ of Applied Economics for International Trade and Commerce, Shanghai University, Shanghai, China \\ Correspondence: Qiang Jiang, Ph.D of Applied Economics for International Trade and Commerce, Shanghai \\ University, Shanghai, China.
}

Received: June 23, 2017

Accepted: July 7, 2017

Online Published: July 25, 2017

doi:10.5430/ijfr.v8n3p195

URL: https://doi.org/10.5430/ijfr.v8n3p195

\begin{abstract}
The backward economies can't enter into the high-income group after stepping on the middle-income stage successfully. Based on multidimensional perspective of economics, this paper will analyze the reasons of "middle-income trap". As the adverse condition of international environment and domestic weakness, the development process of backward economies when they enter into the "middle income trap" is generally affected by the global economic crisis, while it is difficult to resist the global economic crisis for the middle income stage because its vulnerability. Turning to another views, the lower domestic savings rate, the shortage of high-end production factors, the low degree of market standard, the low-end embedded international production system will hinder the middle-income economies to enter into high-income group. The analysis of this paper in details will provide reference for China and provide theoretical support and policy guidance for its rapid entry into high - income economies.
\end{abstract}

Keywords: medium-income trap, multidimensional perspective analysis

\section{Introduction}

According to the World Bank's definition to middle-income trap, economies whose per capita GNI is ranging from 2006 to 12275 are collectively referred to middle-income economies. On the process of world development, backward countries will face the reality that they will experience from middle-income stage to high-income economy in the process of economic catching-up inevitably. However, some economies have long been in the middle income stage and can't enter the high-income group easily. While "East Asian Tigers" and Japan have used a relatively short period to enter into high-income economies for the same process successfully, and even show better expectation of economic growth. The following Figure 1 shows the change trend in GNI of Brazil, Indonesia, Japan, Mexico, Poland and South Korea from the 1970s to 2015.

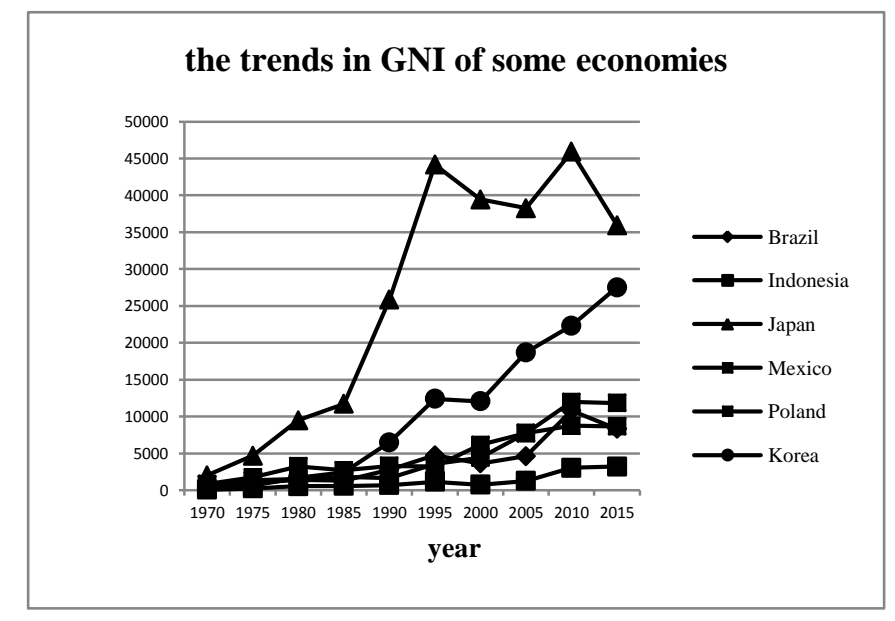

Figure 1. Trends in GNI of some typical economies

Source: United Nations database 
According to Figure 1, in the 1970s, the six economies were nearly at the same level of economic development and began the process of catching up to western developed capitalist countries. Japan spent more than ten years to enter into high-income group from the middle income stage successfully. South Korea spent 17 years to become a high-income economy in 1994 by after Japan's step. Although experiencing the Southeast-Asian financial crisis, Korean once slashed sharply, then its economic growth quickly continued to develop towards good expectation. When turning to other four economies, after nearly 45 years, their economy has not gained much progress and can't enter into developed economies group like Japan and South Korea. Brazil has joined the middle-income group since 1976, but until 2010 that it had joined successfully the group of high-income economies. Unsteadily, Brazil was in recession and backed to middle-income group in 2015. Again it spent 35 years to get out of the middle-income stage while the economic foundation is still not strong enough. Indonesia succeed in getting out of poverty from 1994 and entered the middle-income stage, but after 21 years of development, as of 2015, the country's GNI is only \$ 3230 . The time for Mexico and Poland to be trapped in the middle-income stage still keeps longer than Brazil and Indonesia. Even if Poland broke through the middle-income stage in some years, it did not show the same vitality as Japan and South Korea but was still wandering in the upper edge of middle-income stage defined by the World Bank. Figure 1 shows only the development of six typical economies and there are still many economies which are trapped in the middle income stage for long time. In 2007, the World Bank, for the first time in the study of East Asian economies, proposed the concept of "middle-income trap", which argued that if an economy could not smoothly join the group of high-income economies, the economy will fall into the "middle income trap". Also, the world's three major regions have been included in the hardest-hit area of middle-income trap: Latin American economies, followed by the Southeast Asian economies and the Eastern European economies as the last. While taking research on economic growth of East Asian economies, World Bank set the "East Asian Tigers" and Japan as successful models which have got over middle -income trap.

So, what is the reason that makes such a large heterogeneity between backward countries in the process of economic catching-up? And what is the difference of economic growth pattern between East Asia, Japan and countries that are caught in the middle-income trap? Some scholars have explained the phenomenon of middle-income trap from some angles, for a purpose to provide reference for China that is taking the process of economic catch-up. However, since the study of economic growth has a systematic feature, analysis from a specific perspective rather than from the overall view will obviously affect our overall perception of the middle income trap.

China has entered a critical period that it need get over the middle income stage and whether the current development trend of China can get rid of the middle income trap is one of the most important issues in academia. Lin Yifu takes the view that China can quickly get rid of the middle income stage and enter the group of high-income economies before 2025. However, a series of problems also generate our concern of the expectation of future economic growth such as the gradual decline of China's economic growth, the gradual weakened marginal role taken by the real estate market, the disappearance of labor force dividend, increasingly prominent energy and environmental resources constraints, overcapacity and asset bubbles. The current empirical study on middle-income trap is mainly based on the study of East Asia, Japan and Latin America and Southeast Asia. Deeply exploration of the external international environment and the heterogeneity of the internal economic growth pattern faced by these two kinds of economies in the process of economic catch-up can help us to understand the factors which could explain the middle-income trap and provide theoretical reference and policy reference to China. The next parts are arranged as follows: Section 2 is the literature review which systematically expounded the explanation of early scholars about the middle income trap; Section 3 analyzes the difference between the four small economies of East Asia and economies of Southeast Asia and Latin America from the perspective of international environment; Section 4 analyzes the difference between the two from the perspective of the domestic economic growth model; Conclusion is the last part.

\section{Literature Review}

Some scholars take the view that there is a certain degree of scientificity and rationality for middle-income trap, but some scholars think that this is only the difference of duration time of different economies in the middle-income period. Hua and Ji (2015) carried out analysis and discussion on the topic of "middle income trap" and thought that by adopting income level and the duration time of same income to define the "middle income trap" has obvious shortage. However, according to Figure 1, some economies do stay at middle-income for a long time, or even just get out of the stage. In a weak external economic surrounding and under internal economic fluctuations, overing middle-income period become to be difficult, which also shows that the world Bank's definition of "middle income trap" is not unreasonable. For present, we can call the economies which have long remained in this income range "middle-income trap". Many scholars have carried out a multi-dimensional research and analysis on why some economies get caught in the middle-income trap for a long period. Zheng (2011) argues that the widening gap 
between the rich and the poor is the main cause that hinders the continued growth of the economy and takes Latin America as an example to show the negative effects of social stratification on economic growth. This view has also been recognized by Vandenberg \& Zhuang (2011) who takes China as an example, illustrating that if China wants get over the middle-income trap smoothly, it must correct the wealth deviation between the rich and poor and turn the distribution of social wealth to be more fair. Jankowaka et al. (2012) thinks that the dislocation of internal demand and industrial development are important factors which leads to middle-income trap. Taking Latin American and East Asian economies as examples, this paper systematically analyzes the consistency between the industrial structure and the internal demand of East Asian economies, and at the same time pointed out that the single industrial structure and slow pace of industrial upgrading of Latin American industries has led to slow urbanization, thus hindering the further growth of economy. Ohno (2009) also got the same conclusion in his study on Southeast Asian economies, in which he argued that if the industrial structure could not be upgraded successfully or the government policies could not be followed up in time, then economic stagnation would appear naturally. Cai $(2010,2012)$ explores the relationship between demographic dividend and economic growth from the perspective of population economics. Before the inflection of Lewis, the demographic dividend did not disappear, and the large amount of labor released from the agricultural sector could be immediately transformed into industrial workers, acting as an unskilled labor force in the international production system, thereby boosting economic growth. But when the level of economic development enter into middle-income stage, it will face the arrival of Lewis turning point that the labor force can not shift from the expansion of quantity to quality, and human capital level would not be improved and its economic growth will stagnate.

Zhang (2013) analyzes the mechanism of the "middle-income trap" based on the dynamic heterogeneity required at different stages of economic growth. He argued that the reason why Latin American and Southeast Asian economies have long been caught in the middle-income period is that these economies still rely on the growth model in the initial stage of economic growth when they enter into a higher level of development. Form a contrast, the economic growth of high-income economies depends mainly on technological progress, the upgrading of human capital level and the renewal of material capital, rather than a lot of investment of low-standard production factors. But the model of economic growth in Latin America and the Southeast Asian economies remains unchanged and does not achieve the transformation of economic growth model. Kong (2011) further complements the characteristics of the economies caught in "middle-income trap" from the innovation capacity and the fragility of financial system. Cai (2011) further pointed out from the sociological angel that the impact of social hierarchical consolidation on economic growth. The increasingly consolidated social system would stifle the vitality of social class transformation and the production factors in the production areas also could not be promoted and released. Fixed distribution path will be formed in the distribution area and the economic growth model will also be consolidated due to consolidated social hierarchical system. This view has been further recognized by the Department of Sociology, Tsinghua University (2012). As for why the economies would be caught in the middle income period for long time, We argue that the political, economic, social, historical and other factors will all affect this issue. large numbers of scholars from various perspectives also have done research and demonstration. But the academia has not done the analysis and research based on the economic whole-perspective but only proved a certain aspect of reason for economic growth. However, the multidimensional factors of economic growth are connected with each other. On this basis, we would make a full perspective analysis about the factors of formation of middle income traps and the analysis is mainly from the aspects from both home and abroad so to take full use of the economic data for research and demonstration.

\section{The Impact of Foreign Environment on the Middle-Income Economies}

Compared to low-income economies and high-income economies, middle-income economies are the economic groups which are vulnerable to the international economic crisis. Low-income economies are less integrated into the international production syetem, so their relative closed and conservative economic growth pattern isolated their process of economic globalization and world integration. Also because of the self-sufficiency pattern in which these economies depend more on the production and consumption of domestic market that they are in the group of low-income economies. High-income economies have completed the primitive accumulation of capital with their economic growth more relying on technological progress and industrial upgrading. The momentum driving the economic growth more inclined to the development of the service industry. So, even when facing global economic crisis, they can quickly achieve self-correction in the next few years, and soon returned to the high level as the time before economic crisis. The middle-income economies are the most vulnerable economic group which lie between low-income economies and high-income economies. The modern economic crisis that can be observed are the Asian financial crisis in 1998 and the the global economic crisis triggered by American subprime mortgage crisis. Figure 2 
shows the trends in the per capita GDP of the typical middle-income economies and Korea after the 1998 Asian financial crisis, in order to reflect the impact of external economic environment on the middle-income economies.

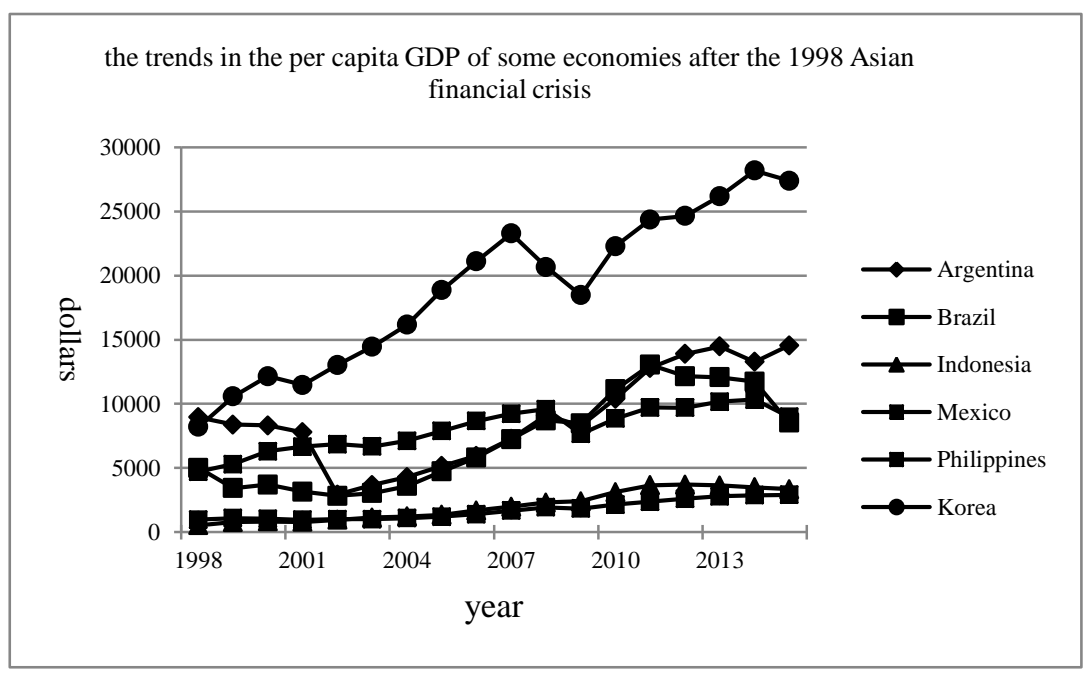

Figure 2

According to Figure 2 above, after the Asian financial crisis in 1998, South Korea has not been much affected, and until 2006, the Korean economy has been keeping rising. Indonesia and the Mexican are relatively stable without being much affected. Because they are still in the group of low-income economies, the economic growth is more dependent on the production and consumption of the domestic market, and their financial system is not integrated into the international financial system, so the impact is still limited. But the impact of Brazil and Argentina, although in the far Latin American region, should not be underestimated. Although Argentina's domestic financial crisis has led to a recession in the Argentine economy, its export is still significant in Argentina's economic growth, with its export accounting for about 15 per cent of GDP for a long period. After 1998, Argentina's exports to the South-East Asian regions were hampered, which further aggravated Argentine economy. Brazil's domestic economy is relatively stable, but the Southeast Asian financial crisis and the global economic crisis have also led to Brazil's eight-year recession, and until 2006, Brazil's economy was gradually restored to the level before the Asian financial crisis. Observation was further given to another global economic crisis which the 2008 US subprime mortgage crisis spread to. After 2008, Brazil, Mexico and Argentina has not developed well as expected while South Korea, which has long entered the group of high-income economies, continues to move in the higher direction after two years of short-term restoration.

The reason why middle-income economies have shown great vulnerability when facing global and local regional economic crises is due to that the global crisis breaks the normal economic development of the middle-income economies while this development path is strongly dependent on the external market environment. A very important factor during the development process of the four tigers of East Asia is that their economies are experiencing the middle-income period within a relatively stable external market environment while the global economy is facing a huge uptrend. In South Korea, for example, South Korea began to enter the group of middle-income economies in 1977 and on this stage the global economy has gradually recovered from the stagflation stage. Technological innovation in the communication fields such as the Internet, computer, electronic technology and the new power characterized by the large-scale universalization of the second industrial revolutionary achievements have gradually become a new impetus for global economic growth. Until 1995, South Korea successfully entered the group of high-income economies. During this period, South Korea actively undertake the export and processing link of the international industrial transfer, taking use of its own advantage and gradually embed in the international production system. Also, it gradually enhances its position in the global industrial chain. At the same time, South Korea's Samsung, LG, Hyundai Motor and other companies gradually gained progress, and with the opportunity to integrate into the global economy, it successfully entered the group of the world's top 500.

According to the two-gap model of Qian Nari's development economics, the developing countries are lack of capital 
and foreign exchange at the initial stage. They then gradually developed to the three-gap model and the four-gap model, when other important factors like technology and entrepreneurial talent added to the factors they lack. And the important way to make up for the two gaps is to introduce foreign investment or loans to meet scarce production factors the gaps need to import from abroad to develop their own. And once these countries loan or import scarce production factors from foreign countries such as technology and talents that they lack, these factors will have a considerable fixed cost and variable costs for late maintenance, which further increases the cost of macroeconomic operation and risk. The high risk of loan interest and the introduction of technology increase the domestic economic leverage. Scarce factors of production, in the case of being taken full use, is conducive to achieving the marginal production of scarce factors, playing a catalytic role for economic growth. At the same time, the factors of production of the same kind are mainly used to undertake the processing of international division of labor. When the external market environment changes, the marginal output of these factors of production will be reduced, or even lower than the fixed production of scarce factors, resulting in that the production factors return back to the origin country and undermining the normal development path of the economy. In Southeast Asia, for example, in the 1980s and 1990s, Southeast Asian economies universally reject foreign capital to get into their own country in order to protect their national industries. But, in order to solve the plight of capital shortage, they borrowed a large amount of short-term loans from abroad through the help of international financing. Also, Under the situation when various economies compete to borrow money, the rate of short-term loan is raised and the cost of capital is enhanced. But after the financial crisis, run of capital happened in order to maintain the capital value, accompanied by the run of high-end and scarce factors of production such as the talent and technology. The flight of scarce production factors directly bring collapse to the economic growth system that has just established.

Compared with middle-income economies, the ability of high-income economies to withstand the external economic crisis greatly increased. Take South Korea as example, the capital is no longer the scarce production factor in the process of development. At the same time, complete infrastructure and potent scientific strength have become important factors that maintain high-end production factors in the economic crisis. Also, when experiencing the economic crisis, developed economies will also take this opportunity to draw high-end production factors from the developing countries and further form Matthew Effect between middle-income economies and high-income economies. Figure 3 shows the situation of capital flows in Indonesia, Korea and Japan before and after the 1998 financial crisis. Indonesia has shown a net inflow in 1995, 1996 and 1997. However, after the 1998 financial crisis, rapid capital flight happened to Indonesian economy. The sum of the capital flows three years after the crisis took roughly the same of the inflows before the crisis. According to Figure 3, substantial inflow of capital happened in South Korea and Japan after the crisis. From capital, a typical production factor, we can speculate the logic of capital flow of high-end production factors like technology and talent between countries after the crisis. Therefore, compared to high-income economies, it is more difficult for middle-income economies in the process of economic development to resist the impact of external economic crisis.

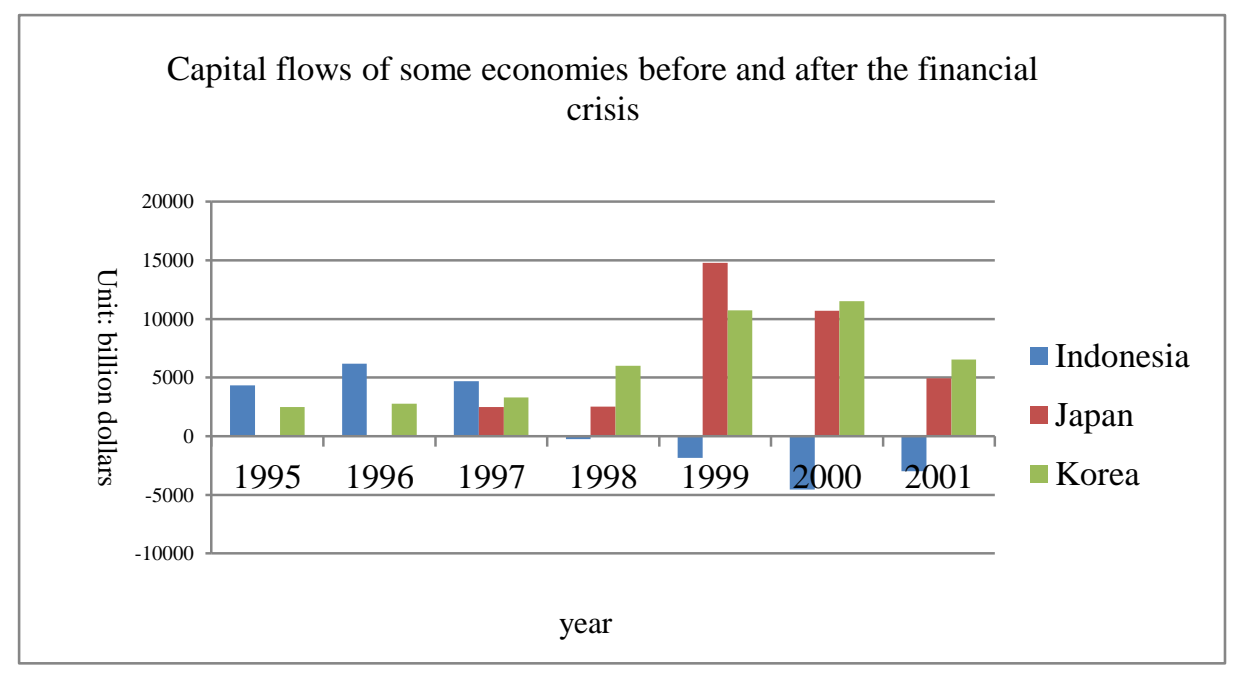

Figure 3. Capital flows of some economies before and after the financial crisis 


\section{Analysis of Domestic Economic Attribution for "Middle-income Trap"}

The overall environment of economic development of the world imposes a very serious impact on the middle-income economies. Meanwhile, there exist a series of common domestic features among economies caught in "middle income trap", which further lead these economies to sink into the middle-income stage and can not escape in short period. We analyze the domestic economic attribution of the middle-income trap from the four dimensions of capital accumulation, cultivation of production factors, market environment and export.

\subsection{The Accumulation of Capital Lag behind the Process of Capital Deepening}

During the process of economic growth, capital is one of the important production factors. The reason of difference between East Asian economies and Southeast Asian economies after entering the middle income period lies in that the East Asian economies pay more attention to capital accumulation and the East Asian economies have higher savings rates. Figure 1 shows the date of savings rate of some middle-income economies such as South Korea, United States.

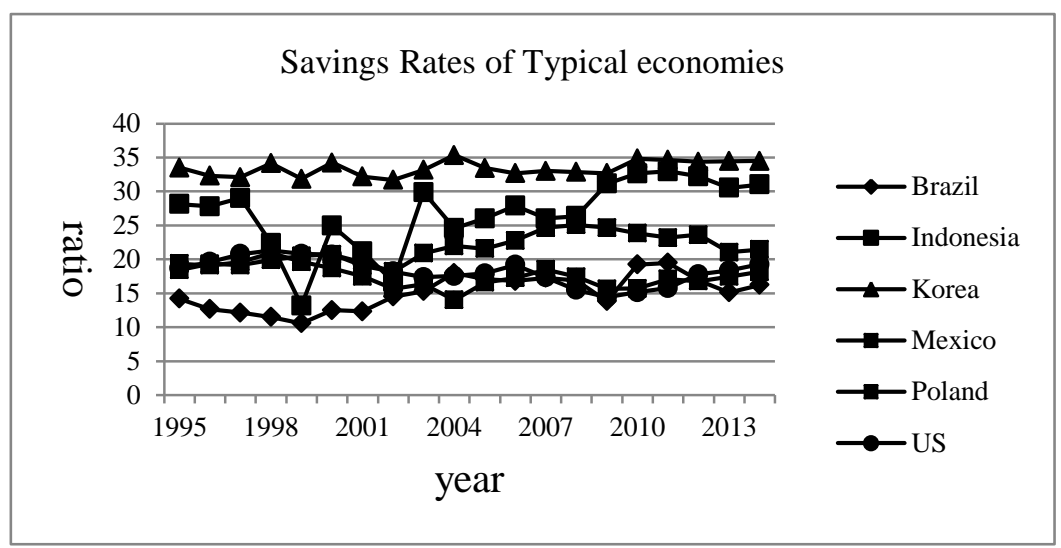

Figure 4. Savings rates of typical economies

According to Figure 4, the saving rates of Brazil, Indonesia, Mexico, Poland are generally lower than that of South Korea. Although the saving rate of Indonesia in some years is close to South Korea, but the change of its saving rates over the years shows a large variance. Due to the dollar's international currency status and strong scientific and technological strength, the United States is still not lack of capital in maintaining low saving rates after entering the group of developed economies. At the same time, we further calculated the capital stock of the six economies in Table 1 on the basis of the perpetual inventory method. The specific formula is as follows:

$$
\mathrm{K}_{i t}=\frac{K_{i t-1}}{1-\delta}+I_{i t}
$$

Among this, $\mathrm{K}_{i t}$ represents the material capital stock of each country in period of $\mathrm{t} . \mathrm{K}_{i t-1}$ represents the material capital stock of each country in the period of $\mathrm{t}-1$, and $\delta$ represents the material capital depreciation rate, and $\mathrm{I}_{i t}$ represents the input flow of material capital of each country in the period of $t$. In order to unify the material capital stock to the price level of the base period, we discount the input flow of material capital into the level of base period through the investment price index of fixed assets of countries over the years. $\delta$ is the capital depreciation rate. Based on Coe \& Helpman (1995) logic, the specific calculation formula of the material capital stock of the countries in the basic period of 1995 is as follows:

$$
K_{i t}=I_{i t} /(g+\delta)
$$

Among this, $g$ is the geometric growth rate of fixed asset investment in countries for the past three years from 1995 to 1998 . $\delta$ is the capital depreciation rate. We used the measured result of $9.6 \%$ made by Zhang (2004) and the specific accounting result is showed in Table 1. 
Table 1

\begin{tabular}{|c|c|c|c|c|c|c|}
\hline Year & Brazil & Indonesia & South Korea & Mexico & Poland & the US \\
\hline 1995 & 1388.822 & 53.77981 & 2711.356 & 207.3486 & 107.5952 & 8968.701 \\
\hline 1996 & 1394.488 & 57.92834 & 2795.889 & 262.0753 & 128.317 & 10235.84 \\
\hline 1997 & 1324.763 & 55.03193 & 2656.095 & 248.9715 & 121.9011 & 9724.05 \\
\hline 1998 & 1329.161 & 53.71569 & 2619.019 & 315.1971 & 146.8078 & 11270.2 \\
\hline 1999 & 1307.972 & 52.27947 & 2626.41 & 380.9989 & 169.4338 & 12910.49 \\
\hline 2000 & 1296.173 & 52.75658 & 2665.571 & 457.7272 & 189.7798 & 14635.24 \\
\hline 2001 & 1274.862 & 53.06984 & 2686.865 & 522.6758 & 206.6866 & 16192.66 \\
\hline 2002 & 1244.812 & 53.78488 & 2725.226 & 585.0247 & 220.9016 & 17697.1 \\
\hline 2003 & 1215.489 & 55.86222 & 2788.087 & 640.2139 & 237.227 & 19246.98 \\
\hline 2004 & 1194.11 & 57.8598 & 2872.629 & 699.1192 & 259.2967 & 20983.18 \\
\hline 2005 & 1182.418 & 60.30861 & 2992.096 & 762.149 & 286.0455 & 22899.24 \\
\hline 2006 & 1182.314 & 63.90149 & 3143.877 & 835.7248 & 320.2016 & 24904.57 \\
\hline 2007 & 1202.435 & 68.10848 & 3319.149 & 911.0876 & 373.3551 & 26810.37 \\
\hline 2008 & 1241.04 & 73.84961 & 3453.176 & 990.7824 & 437.6933 & 28447.46 \\
\hline 2009 & 1259.081 & 80.58234 & 3512.491 & 1034.886 & 472.0871 & 29482.2 \\
\hline 2010 & 1311.959 & 89.97449 & 3652.582 & 1086.522 & 511.6303 & 30685.68 \\
\hline 2011 & 1375.395 & 100.8699 & 3826.389 & 1145.14 & 558.5069 & 31949.12 \\
\hline 2012 & 1419.033 & 112.355 & 3975.65 & 1204.236 & 594.1309 & 33389.31 \\
\hline 2013 & 1456.121 & 122.2146 & 4117.937 & 1259.156 & 624.5626 & 34923.62 \\
\hline 2014 & 1479.715 & 131.1326 & 4282.716 & 1310.83 & 660.3082 & 36556.59 \\
\hline
\end{tabular}

Based on the data in Figure 4 and Table 1, it can be seen that South Korea's saving rate is higher than that of Southeast Asian economies and Latin American economies. It is just the high saving rate that leads to the rapid accumulation of Korea's capital stock. According to Table 1, Korea's capital stock showed a rapid rising trend while the capital accumulation of Southeast Asian economies is relatively slow and in some years even did not grow. Little amount of capital had been retained for the capital stock in the next period after the output of the year covered the domestic consumption and depreciation. This has seriously constrained the economy to develop toward the direction of high-income economies. According to the Solow model, capital and labor is the basic production factors in the economic growth. Economies caught in the middle-income trap is still low in per capita capital occupancy. Compared with developed economies and emerging economies, the lower saving rate restricts the capital deepening.

\subsection{High-end Production Factors Have Not Been Timely Cultivated}

In addition to capital accumulation, the cultivation of production factors is also very important. The biggest difference between the middle-income economies and the high-income economies lies in the difference of the economic growth patterns. The high-income economies rely on innovation and the high value-added of the high-end industries to achieve the high-level economic operation. However, the middle-income economies rely mainly on low-end production factors and embed themselves in the production and processing of international production system. The economic growth of these economies is at the expense of their own resources and environment. Extensive input of production factors is the dominant factor to support economic growth. Therefore, the middle-income economies need to cultivate well the high-end production factors, especially the human capital level, which is needed in innovation and the development of high-end industries in its process of becoming high-income economies. Based on this, we further contrast the gap of human capital level between economies caught in middle-income stage for long period of time and Korea. At present, there is not data of human capital level of each country in domestic and foreign database which has finished the accounting. Currently, there are mainly three kinds of research methods of accounting for human capital level: input accounting method of human capital, output 
accounting method of human capital and accounting of the national citizens' quality from educational perspective. Neither of the first two methods is ideal when calculating the cross-border human capital level. Since there exists gap between input efficiency of different economies and in the output process the input efficiency was affected by the level of their own economic development, it is very difficult to reflect a country's real human capital level through the input method and output method. Through the method of Barro \& Lee (1996), we use the per capita education years as an index of the human capital level of the economy. The specific accounting formula is as follows:

$$
\mathrm{E}_{t}=\frac{\sum_{i} L_{i t} U_{i}}{L(t)},(\mathrm{i} \text { represent the primary school, the junior }- \text { high school and middle }- \text { high school) }
$$

In this formula, $U_{\mathrm{i}}$ represents the education years needed by the completion of all types of education, $L_{\mathrm{it}}$ represents the population who completed the education of type $\mathrm{i}$ in the year of $\mathrm{t}, L(t)$ is the total population in the year of $\mathrm{t}$. The raw data comes from the World Bank Database. Table 2 presents the level of human capital in some typical middle-income economies and South Korea.

Table 2

\begin{tabular}{llllll}
\hline Country & & & & & \\
\hline 1995 & Brazil & Indonesia & South Korea & Mexico & Poland \\
1996 & & & & & \\
1997 & 5.58 & 4.62 & 10.49 & 7.20 & 9.86 \\
1998 & 6.82 & 4.75 & 10.63 & 7.32 & 9.96 \\
1999 & 6.05 & 4.89 & 10.78 & 7.43 & 10.06 \\
2000 & 6.27 & 4.97 & 10.87 & 7.51 & 10.13 \\
2001 & 6.52 & 5.01 & 10.91 & 7.54 & 10.15 \\
2002 & 6.67 & 5.15 & 11.06 & 7.66 & 10.26 \\
2003 & 6.80 & 5.60 & 11.14 & 7.82 & 10.40 \\
2004 & 6.96 & 5.87 & 11.20 & 7.94 & 10.50 \\
2005 & 7.13 & 6.14 & 11.29 & 8.11 & 10.65 \\
2006 & 7.29 & 6.41 & 11.46 & 8.28 & 10.79 \\
2007 & 7.41 & 6.65 & 11.58 & 8.45 & 10.94 \\
2008 & 7.53 & 6.89 & 11.70 & 8.59 & 11.02 \\
2009 & 7.64 & 7.12 & 11.81 & 8.65 & 11.09 \\
2010 & 7.76 & 7.36 & 11.93 & 8.72 & 11.17 \\
2011 & 7.88 & 7.60 & 12.05 & 8.79 & 11.24 \\
2012 & 8.04 & 7.92 & 12.21 & 8.88 & 11.32 \\
2013 & 8.19 & 8.23 & 12.36 & 8.97 & 11.42 \\
2014 & 8.36 & 8.57 & 12.53 & 9.07 & 11.52 \\
\hline & 8.48 & 8.81 & 12.65 & 9.14 & 11.71 \\
\hline
\end{tabular}

According to the table above, South Korea's per capita education level is relatively high, nearly equal to the due level of the developed economies. Brazil, Indonesia, Mexico are relatively lagging behind, and even their development at the current stage is not up to the level of Korea in the 1980s. Poland, although relatively high in its per-capita education level, but as an Eastern European economy, the impact of the former Soviet Union led to that large number people of Poland received education but without high quality. The overall level of its economic development is relatively backward, so its per capita education years can not be mentioned in the same breath as that of the South 
Korea. It is imperative that the middle-income economies wish to smoothly overcome the middle-income stage in order to enhance their high-end production factors. The gap of high-end production factors represented by human capital is sufficient to reflect the direction that the middle-income economies strive for.

\subsection{The Market Mechanism Needs to Be Further Perfected}

In the configuration process of production factors, planned-economy and market economy are two ways for the allocation of resources. The results of the economic growth pattern of the former Soviet Union and the United States and Europe have fully demonstrated that the market is one of the most effective ways of resource allocation at present. In the past, after Soviet economy's rapid entering into the middle-income stage, its further development ran into trouble, in which planned-economy obstructed the way. To form a contrast, American and European economic growth patterns rely on market's allocation of resources for long period of time and have achieved rapid economic development. Based on this, we believe that the level of marketization is also an essential factor causing that the middle-income economies can not enter into the group of high-income economies. According to Fan's accounting method (2003) of China's marketization index, we select the three-dimensional indicators to calculate the countries' marketization index to probe into the impact of marketization index on the middle-income trap. There are various factors which can affect the level of marketization, but they are basically included in the three core categories: relation between government behavior and market, free distribution of production factors and whether the market system is perfect. Researches from more dimensions can be carried out for the calculation of the marketization degree of different areas within the same economy, but there exists great difference in the historical development process, the level of economic development and the social system of different economies. So we based on the three core categories which can reflect the level of marketization to calculate the index of marketization of the economies over the years. According to the availability of the data, we take the proportion of R\&D personnel working in the private sector in the total number of staff to reflect the level of free allocation of production factors, the proportion of government expenditure in GDP to reflect the relation between government behavior and market and the number of patent applications of every one thousand people in various economies to reflect whether the market system is perfect. As for how to synthesize the three-dimensional index to the data of the aggregate's marketization index, by drawing on the method of Fan (2003), we transform the actual value of the three indicators into a relative index of one-point scale. Take the proportion of R\&D personnel working in the private sector in the total staff for example and according to the liquidity of production factors, the production factors of the private sector, which are basically arranged according to the price of the production factors, are more mobile than that of the non-private sector. Therefore, the larger proportion of the production factors in the private sector is, the higher level of marketization would be. As the time of the data covers from 1995 to 2014, the base period is set as 1995 . When it comes to the proportion of $\mathrm{R} \& \mathrm{D}$ personnel working in the private sector, one economy's lowest proportion of R\&D personnel in the private sector in 1995 is set as zero while another economy's highest proportion is set as 1 . On this basis, the corresponding score can be determined by comparison of other economies' proportion between 0 and 1 , the specific formula is as follows:

$$
\frac{\mathrm{S}_{i}-S_{\min }}{S_{\max }-S_{\min }}
$$

Among this, $\mathrm{S}_{\max }$ is the index maximum during the base period while $S_{\min }$ is the minimum and $S_{i}$ is the individual indicator value that needs calculation. The individual calculation result during the base period of 1995 is distributed between 0 and 1 . But with the development in later years, the calculation value would possibly be larger than 1 or less than 0.

However, larger value of some indicators does not always mean better marketization degree. Take the percentage of government expenditure in GDP for example and according to the relation between the government and the market, higher government expenditure represents that government has posed greater intervention to the market, which would accordingly occupy the scale of expenditure of the individual consumers in the market. There exists unavoidable rent-seeking behavior in the process of government's expenditure. At the same time, since the government has its own plan, the expenditure can't really reflect the market demand of the individual consumers. So, the degree of marketization is higher when government's ability to impose intervention to the market is weaker because of less government expenditure. Under this circumstance, the above calculation formula would produce outcome contrary to the logic. Therefore, we present the calculation formula under this circumstance as follows:

$$
\frac{S_{\max }-S_{i}}{S_{\max }-S_{\min }}
$$


The description of specific indicators is as same as the above content. When synthesizing the three-dimensional indicators to form the index of integral marketization, we adopt the practice of American Heritage Foundation and endowed the three-dimensional index with the same weight to calculate the overall marketization index. The specific calculation is as follows. Limited by the length of the paper, we reported the marketization index of some economies every five years and made a line chart for the trend of marketization change of the six economies from 1995 to 2014: Brazil, China, India, Japan, Russia and the US.

Table 3

\begin{tabular}{lllllll}
\hline $\begin{array}{llllll}\text { Country } \\
\text { Year }\end{array}$ & Brazil & China & India & Japan & Russia & the US \\
\hline 1995 & 0.838502 & 0.662374 & 0.359654 & 2.794903 & 1.131755 & 1.632462 \\
\hline 1996 & 0.814157 & 0.693948 & 0.376023 & 2.862588 & 1.159501 & 1.600535 \\
\hline 1997 & 0.826079 & 0.657109 & 0.384143 & 2.957311 & 1.13574 & 1.610551 \\
\hline 1998 & 0.813233 & 0.550682 & 0.40897 & 2.994737 & 1.090612 & 1.637501 \\
\hline 1999 & 0.814179 & 0.594202 & 0.446905 & 3.00892 & 1.071983 & 1.692443 \\
\hline 2000 & 0.794558 & 0.913036 & 0.492257 & 3.064502 & 1.112876 & 1.748295 \\
\hline 2001 & 0.782859 & 0.936217 & 0.478355 & 3.178799 & 1.114847 & 1.802783 \\
\hline 2002 & 0.769593 & 0.978815 & 0.473769 & 3.130582 & 1.121746 & 1.830293 \\
\hline 2003 & 0.717565 & 1.007034 & 0.484817 & 3.132011 & 1.110653 & 1.850649 \\
\hline 2004 & 0.718493 & 1.026465 & 0.535798 & 3.146648 & 1.065322 & 1.870659 \\
\hline 2005 & 0.746667 & 1.13223 & 0.572686 & 3.178689 & 1.026575 & 1.930107 \\
\hline 2006 & 0.709953 & 1.169275 & 0.604266 & 3.086338 & 1.049689 & 1.991897 \\
\hline 2007 & 0.6748 & 1.228292 & 0.605613 & 3.028332 & 1.049319 & 2.045042 \\
\hline 2008 & 0.643083 & 1.281997 & 0.612677 & 3.08183 & 1.057422 & 2.035052 \\
\hline 2009 & 0.604779 & 1.171405 & 0.620885 & 2.897646 & 1.0522 & 2.091486 \\
\hline 2010 & 0.567513 & 1.196929 & 0.648365 & 2.877322 & 1.027838 & 2.156479 \\
\hline 2011 & 0.542578 & 1.277358 & 0.636863 & 2.875106 & 1.021765 & 2.129795 \\
\hline 2012 & 0.546945 & 1.33459 & 0.633516 & 2.871894 & 1.00729 & 2.216345 \\
\hline 2013 & 0.535206 & 1.411813 & 0.628673 & 2.789203 & 1.02796 & 2.275862 \\
\hline & & & & & & \\
\hline
\end{tabular}

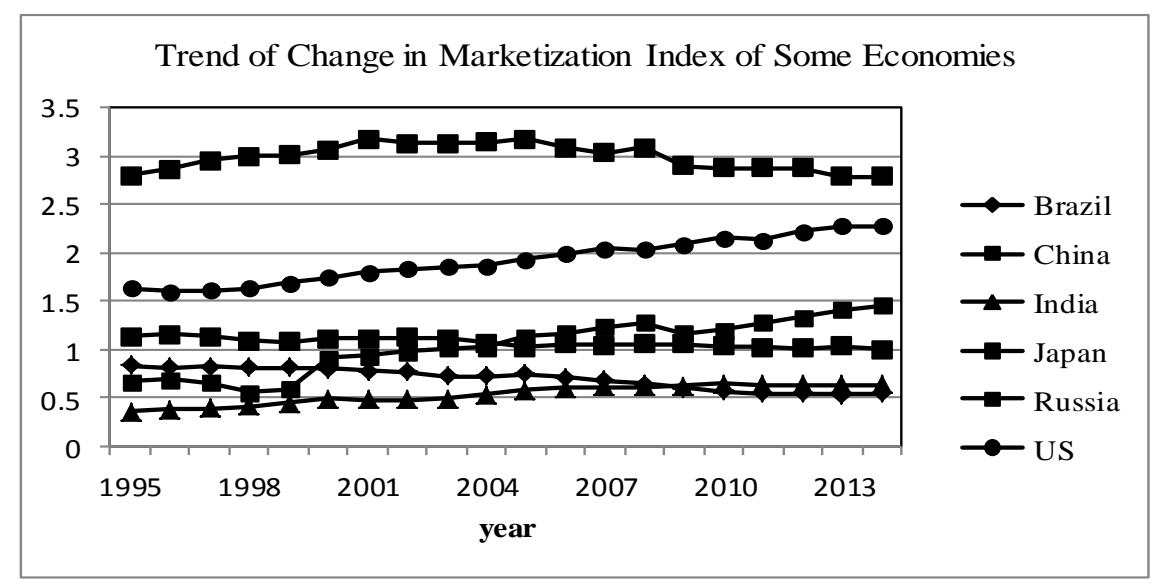


According to the data reported in the table and the trend showed from the line chart about the marketization index of some economies: the marketization index of Japan is still the highest, followed by the United States. But Japan has already reached very high level of marketization in 1990s. China's level of marketization has achieved the most obvious progress and has exceeded that of the other three brick economies: Brazil, India and Russia. Although the marketization degree of India is not very high, it has been witnessing the continuous rise while the marketization degree of Brazil and Russia is confronted with decline, forming larger gap with the developed economies. From the statement about the above six economies, it can be proved that the the economy of Brazil and Russia have been caught in the middle-income stage for the longest time. This also shows the impact of marketization level on the middle-income stage.

\subsection{Low - end Export}

Nowadays, the process of globalization and integration of the world economy is accelerating. Every country has become an organ of the world economic growth. The economic growth of the developed countries is inseparable from the developing countries and vice versa. From inter-industry trade to intra-industry trade and even today's intra-product trade stage, the international division of labor is more refined, and the behavior of international investment along with the international trade has brought global economic integration to a new height. As an important driving force for economic growth, export trade has been used thoroughly by the economy in the process of economic catch-up. However, the expansion of the total export trade has not promoted the quality of export trade nor its impact on economic growth is very obvious. For example, as Southeast Asian economies implement long-term export-oriented economic growth strategy, their proportion of export trade in GDP has been far higher than that of developed economies, but their per capita GDP has not been upgraded with the expansion of export trade which depends more on quantity rather than quality. The export added-value which embodies the true value of export trade is not high, and industries which create export value-added are mainly concentrated in the agricultural sector and low-end manufacturing sector.

According to the method of Stehrer (2012), we use the world non-competitive input-output table between 2000 and 2014 for accounting and form complete data of export trade value-added of various years at the total-volume level and industrial level. Meanwhile, according to OECD's classification and aggregate of different industries, the data of added-value of export trade in the six major industrial sectors is made and these six sectors are the agricultural sector, the low-tech manufacturing sector, the medium-low-tech manufacturing sector, the medium-high-tech manufacturing sector, the high-tech manufacturing sector and the service sector. Due to the limited length, this paper only makes report on the industrial composition of the export trade value-added of some typical economies in 2014.

Table 4

\begin{tabular}{|c|c|c|c|c|c|c|c|c|}
\hline Country & \multicolumn{2}{|c|}{ China } & \multicolumn{2}{|c|}{ Germany } & \multicolumn{2}{|c|}{ Brazil } & \multicolumn{2}{|c|}{ South Korea } \\
\hline & Value-added & Share & Value-added & Share & Value-added & Share & Value-added & Share \\
\hline Agricultural Sector & 53298.7 & $2.05 \%$ & 12400.8 & $1.19 \%$ & 45907.8 & $17.44 \%$ & 1235.0 & $0.29 \%$ \\
\hline Low-tech Sector & 529144.9 & $20.35 \%$ & 55732.9 & $5.35 \%$ & 88659.3 & $33.68 \%$ & 25227.0 & $5.94 \%$ \\
\hline $\begin{array}{l}\text { Low-high tech } \\
\text { sector }\end{array}$ & 676192.6 & $26.00 \%$ & 147228.2 & $14.13 \%$ & 30385.9 & $11.54 \%$ & 74704.6 & $17.59 \%$ \\
\hline $\begin{array}{l}\text { Middle-high tech } \\
\text { sector }\end{array}$ & 393043.0 & $15.11 \%$ & 328465.8 & $31.53 \%$ & 14016.9 & $5.32 \%$ & 128600.9 & $30.29 \%$ \\
\hline High-tech sector & 431523.1 & $16.59 \%$ & 266764.5 & $25.60 \%$ & 44767.8 & $17.01 \%$ & 121632.4 & $28.65 \%$ \\
\hline Service sector & 517440.7 & $19.90 \%$ & 231259.1 & $22.20 \%$ & 39512.9 & $15.01 \%$ & 73199.7 & $17.24 \%$ \\
\hline
\end{tabular}

In order to further highlight the difference of proportion of department composition in the four typical economies of China, Germany, Brazil, and South Korea, the following pie chart shows the composition of department of export trade value-added of the four economies. 
Composition of department of export trade added-value of Brazil

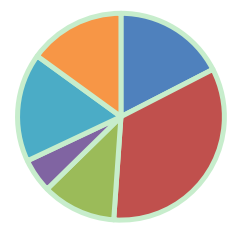

- agricultural sector $\quad$ - low-tech sector $\quad$-middle-tech sector

- middle- high-tech sector " high-tech sector

- service sector

Composition of department of export trade added-value of China

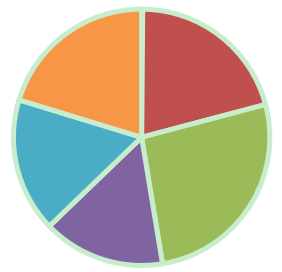

- agricultural sector - low-tech sector middle-tech sector

- middle- high-tech sector $₫$ high-tech sector $\quad$ service sector

Composition of departmnet of export trade added-value of Germany

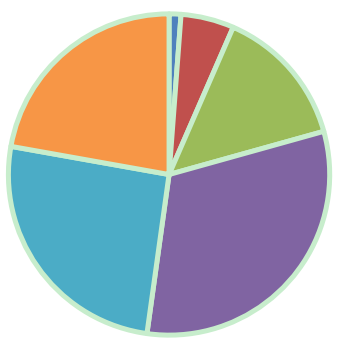

- agricultural sector

- low-tech sector

- middle-tech sector

- middle- high-tech sector $=$ high-tech sector

- service sector

Composition of department of export trade added-value of South Korea

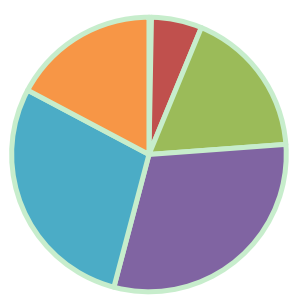

- agricultural sector $\quad$ - low-tech sector

- middle-tech sector

- middle- high-tech sector $=$ high-tech sector

= service sector 
China, Brazil, Germany and South Korea represent respectively the medium-large-scale developing economy, economy caught in the "middle-income trap", developed economy and emerging economy. By probing into the sector structure of export trade value-added, the composition of export trade value-added industries in the four types of countries can be reflected in a certain degree. In the composition of Brazil's value-added of export trade, the agricultural sector contributed the most, followed by the low-tech sector while the export trade value-added of agricultural sector and low-tech sector has accounted for half of the Brazilian export trade value-added. China's proportion of export value-added of agricultural sector has reduced to the level of developed countries. Due to China's large population, the agricultural sector output is mainly used to meet the needs of their residents. Government's policy guidance and the need to maintain their own food security led to China's relatively low agricultural sector exports. In addition to the agricultural sector, the composition of China's export trade value-added industries is relatively dispersed, but mainly concentrated in the low-tech sector and medium-low-tech sector. The value-added of Germany's export trade is mainly concentrated in the medium-high-tech sectors, high-tech sectors and service sectors. The value-added created by these three sectors accounts for $80 \%$ of the value-added of Germany's export trade. South Korea's situation is similar to Germany, but the proportion of the medium-low-tech sector is slightly higher than that of Germany while the proportion of the service sector is slightly lower than that of Germany. Overall, the industrial composition of Germany's export trade value-added is more scientific and reasonable.

Based on the analysis of the value-added industry composition, Brazil, as a typical representative caught in the "middle-income trap", has a relatively low-end composition of its export trade earnings and lower quality of overall export trade. Even for China whose level of economic development is low, its industrial composition of export trade is still more reasonable than Brazil. So, economies caught in the middle-income stage for long period of time need to change the industrial structure of their export trade earnings.

\section{Conclusion}

From the perspective of economies caught in "middle-income trap", we analyzed the reasons why they cann't enter the high-income economies smoothly from multi-dimensions. The analysis framework is based on international and domestic perspective. From the international perspective, balanced external market surrounding is conducive to the rapid development. According to the historical experience of the world economic development, when the four East Asian Tigers' economies are experiencing economic take-off, period is during the third technological revolution, the Southeast Asian economies, however, suffered the impact of the financial crisis in Southeast Asia for its lagging nature in the initial development. The analysis from the domestic perspective mainly comes from four angles: capital accumulation, high-end production factors cultivation, marketization degree and quality of export. Economies caught in the "middle-income trap" generally have weakness in the four aspects: the low savings rate hindering the process of domestic capital accumulation; the relatively slow speed of technological progress and the high-end production factors which cann't support the domestic industrial upgrading and the quality promotion of economic growth; The way of resource allocation is still unable to achieve complete marketization, undermining the optimal allocation of production factors and commodities; The value-added of the export's real benefits is not high, and the industrial structure which constitutes the value-added is also irrational. The export model dominated by agriculture and low-end manufacturing is bound unable to improve the quality of their economic growth, hindering its development towards high-income economies.

Based on the above analysis and look forward to the development of China's economy in the future, there exist both opportunities and great challenges. After three major revolutions in science and technology, the technical breakthrough is difficult to shake the aftermath brought by the third revolution. The opportunity that the third revolution in science and technology bring to the four East Asian economies is difficult to be copied to China's economic development. The fragility of the world economy and financial system and the consolidated international production system make it difficult for China to break through the obstacles while Europe and the United States and other developed economies suppressed the chance of China's development through blocking the top of the value chain and the taking up the leadership in the field of technology. However, by taking use of the aftermath brought by the third scientific and technological revolution, China also achieved a certain degree of breakthrough. The rise of those outstanding enterprises represented by Alibaba, Tencent, Huawei is enough to explain China's competitiveness in the field of the Internet. From the domestic perspective, China's ability of capital accumulation is strong. After nearly 40 years of development since the reform and opening up, China has get through the situation of capital shortage in ciannelli's two-gap model. But China still faces the lack of comparative advantages domestically, especially the rich labor force in the manufacturing industry. Meantime, China also faces problems like the domestic environmental pollution and ecological destruction, population aging and other issues when the economy has not 
developed to a certain level. Furthermore, the real estate bubble and financial multi-leverages also further weakened China's development potential in the future. Will China join smoothly the group of high-income economies in the future? The above analysis of the perspective will provide some reference at the policy level.

\section{References}

Barro, R. J., \& Lee, J. W. (1996). International Measure of Schooling Years and Schooling Quality. American Economic Review, 86(2), 218-223.

Cai, F. (2010). Demographic transition, demographic dividend and lewis turning point. Economic Research Journal, 4. https://doi.org/10.1080/17538963.2010.511899

Cai, F. (2012). The theory, experience and targeted of "Middle-income trap". Economic Research Journal, 4.

Cai, H. (2011). Maintain high social mobility. New Magazine, 13.

Coe, D., \& Helpman, E. (1995). International R\&D Spillovers. European Economic Review, 39(5), 859-887. https://doi.org/10.1016/0014-2921(94)00100-E

Hua, S., \& Ji, Z. (2015). Middle-income trap or middle-income stage. Economic Research Journal, 7.

Jankowska, A., Nagengast, A., \& Perea, J. R. (2012). The Product Space and the Middle-Income Trap. OECD Development Centre, No.311. https://doi.org/10.1787/5k9909j2587g-en

Kong, J. (2011). What's china should do with the international background and the causes of "Middle-income trap". Reform, 10.

Ohno, K. (2009). Avoiding the Middle-Income Trap: Renovating Industrial Policy Formulation in Vietnam. ASEAN Economic Bulletin, 26(1), 25-43. https://doi.org/10.1355/AE26-1C

Stehrer, R. (2012). Trade in Value Added and the Value Added in Trade. WIOD Working Paper, 1-19.

The Department of Social Group in Tsinghua University. (2012). The "middle-income trap" or "trap" transformation". Open Times, 3.

Vandenberg, P., \& Zhuang, J. (2011). How can China Avoid the Middle-Income Trap?. Asian Development Bank.

Zhang, D. (2013). The mechanism of "Middle-income trap" and the phases of China's economic growth. Economic Research Journal, 9.

Zhang, J., Wu, G., \& Zhang, J. (2004). The material capital estimates in Chinese provincial. Economic Research Journal, 4, 35-43.

Zheng, B. (2011). "Middle-income trap" and China's development path. Chinese Journal of Population Science, 1. 